\title{
Synthesis of Novel Cobalt Doped Zinc Oxide/carbon Nano Composite for the Photocatalytic Degradation of Acid Blue 113
}

\section{S. SUNITHA, A. NAGESWARA RAO* and J. KARTHIKEYAN}

Department of Chemistry, Sathyabama University, Chennai - 600 119, India.

*Corresponding author E-mail: ankemrao95@gmail.com

http://dx.doi.org/10.13005/ojc/310111

(Received: December 06, 2014; Accepted: January 10, 2015)

\begin{abstract}
Cobalt doped Zinc Oxide/Carbon nano composite was synthesized by solution combustion method and characterized by X-ray diffractometer, field emission scanning electron microscope and energy dispersive X-ray spectroscopy analysis. This composite shows X-ray diffraction pattern that matched with nano particle of $\mathrm{ZnO}$ with wurtzite structure and average grain size was found to be $10.53 \mathrm{~nm}$. . Further the presence of the elements like C, Co, Zn and O was confirmed by energy dispersive X-ray spectroscopy analysis. The effect of Co doping on the photocatalytic activity was investigated by photo degradation of the dye, acid blue 113. This nano composite exhibited better photocatalytic activity when compared to nano $\mathrm{ZnO}$ and nano $\mathrm{ZnO} / \mathrm{C}$ composites.
\end{abstract}

Key words: Combustion; Nano composite; Zinc oxide; Carbon; Cobalt.

\section{INTRODUCTION}

Water scarcity and its contamination with organic pollutants cause a host of problems both to the environment and community. The scarcity of water has become a serious concern, with the rapid escalation of industrialization towards a developed society. The waste generated from textile, chemical, mining and metallurgical industries is mainly responsible for contamination of water ${ }^{1,2}$. Semiconductor heterogeneous photocatalysis is a versatile, cost effective and eco-friendly treatment technique for the destruction of organic pollutants in water. Some metal oxide semiconductors such as $\mathrm{Fe}_{2} \mathrm{O}_{3}, \mathrm{ZnO}, \mathrm{TiO}_{2}, \mathrm{WO}_{3}, \mathrm{Cu}_{2} \mathrm{O}, \mathrm{SnO}_{2}$ are being used as photo catalysts ${ }^{3-7}$. Nowadays nano materials are of great interest for research point of view because the properties of the materials change drastically when the particle size reaches to nanometer range. As the size of the material becomes smaller, the band gap becomes larger thereby changing the optical and electrical properties of the material and making the material suitable for newer applications and devices.

Further the use of nanoparticles exhibit higher photo catalytic activity than their bulk counterparts by increasing their surface area and porosity ${ }^{8-10}$. The most commonly used semiconducting metal oxides are $\mathrm{TiO}_{2}$ and $\mathrm{ZnO}$ due 
to their catalytic activity and stability. However, widespread use of $\mathrm{TiO}_{2}$ is not economical for large scale water treatment operations. Ample information has been documented in literature with regard to higher photocatalytic efficiency of $\mathrm{ZnO}$ over $\mathrm{TiO}_{2}$. Moreover, Zinc oxide $(\mathrm{ZnO})$ is an excellent $\mathrm{n}$-type semi conductor with a wide band gap of $3.37 \mathrm{eV}$ and a large excitation binding energy of $60 \mathrm{meV}^{11,12}$. This has attracted the attention of many researchers for the potential use of $\mathrm{ZnO}$ in various photo catalytic reactions ${ }^{13-16}$. Nowadays, many methods are in practice to improve the $\mathrm{ZnO}$ photostability. This includes surface organic coating of $\mathrm{ZnO}^{17}$ and surface hybridization of $\mathrm{ZnO}$ with carbon and fullerenes $C_{60}{ }^{18,19}$. In this connection various experiments have been conducted to enhance the rate of photo degradation of $\mathrm{ZnO}$ by coupling with adsorbent like activated carbon which provides high concentration of target substances around the catalyst particulate ${ }^{20,21}$.

In earlier studies, impurity doping in semiconductor nanoparticles was investigated mainly to enhance the photocatalytic activity, particularly in the UV light region ${ }^{22}$. A number of investigations have focussed on transition metal doped $\mathrm{ZnO}$ semi conductor because of its band gap of $3.37 \mathrm{ev}$, and its large excitation binding energy $(60$ mev) ${ }^{23,24}$. In the present investigation an attempt was made to synthesize cobalt doped nano zinc oxide/carbon ( $\mathrm{ZnO} / \mathrm{C} / \mathrm{Co}$ ) composite. Cobalt was chosen for its expected ease in doping due to the similar ionic radius $(0.058 \mathrm{~nm})$ to that of $\mathrm{Zn}(0.060$ $\mathrm{nm}$ ). The synthesized zinc oxide/carbon/cobalt ( $\mathrm{ZnO} /$ $\mathrm{C} / \mathrm{Co}$ ) nano composite was characterised by various analytical techniques like XRD, FESEM and EDAX. Its photocatalytic activity is compared with nano $\mathrm{ZnO}$ particles and nano $\mathrm{ZnO} / \mathrm{C}$ composite in the degradation of the dye acid blue 113 (AB 113) in water under UV irradiation in the batch reactor.

\section{MATERIALSAND METHODS}

\section{Materials}

The dye, AB 113 commercially known as navy blue S5R with $\mathrm{Cl}$ number 26360 was obtained from local dye suppliers and the dye was used without further purification. The structure of the dye is shown in figure 1. The dye shows an absorption maximum at $565.5 \mathrm{~nm}$. The solutions of desired concentrations were prepared using double distilled water. The other chemicals $\mathrm{Zn}\left(\mathrm{NO}_{3}\right)_{2} \cdot 6 \mathrm{H}_{2} \mathrm{O}$, $\mathrm{Co}\left(\mathrm{NO}_{3}\right)_{2} \cdot 6 \mathrm{H}_{2} \mathrm{O}$ and dextrose were of $\mathrm{AR}$ grade obtained from Merck. The $\mathrm{pH}$ of the solutions was adjusted between 6.0 and 9.0 using dilute solutions of $\mathrm{HCl}$ or $\mathrm{NaOH}$.

\section{Synthesis of $\mathrm{ZnO} / \mathrm{C} / \mathrm{Co}$ nano composites}

$\mathrm{ZnO} / \mathrm{C} / \mathrm{Co}$ nano composite was

synthesized by self propagating solution combustion method ${ }^{25}$. In a typical procedure, $8 \mathrm{~g}$ of Zinc nitrate and $2 \mathrm{~g}$ of Cobalt nitrate were dissolved in $20 \mathrm{ml}$ of double distilled water and $3.6 \mathrm{~g}$ of dextrose was dissolved in $20 \mathrm{ml}$ of double distilled water in separate beakers. Dextrose solution was heated on a hot plate for 5 minutes, when the solution started boiling, the mixture of zinc and cobalt nitrate solution was added drop wise with constant stirring. The solution on dehydration formed a gel like mass. The beaker was heated in a preheated muffle furnace kept at $400^{\circ} \mathrm{C}$. The solution boiled, got ignited and the entire reaction was completed in about 7 minutes. The powder was highly amorphous and the presence of $\mathrm{ZnO}, \mathrm{Co}$ and carbon was confirmed by EDAX analysis.

\section{Photocatalytic reaction procedure}

The photocatalytic degradation of the dye was carried out in a batch reactor of $500 \mathrm{~mL}$ capacity, double walled reaction vessel made of borosilicate glass, having dimensions of $16 \mathrm{~cm} \times 5 \mathrm{~cm}$, mounted suitably on a magnetic stirrer. The photocatalytic experiments were performed under identical conditions by using a low pressure mercury vapour lamp (6W, $18 \mathrm{~cm}$ along) emitting UV radiation at a peak wavelength of $254 \mathrm{~nm}$. Constant stirring of the solution was ensured with the use of a magnetic stirrer. The temperature of the reaction mixture was maintained constant throughout the reaction time. A batch volume of $250 \mathrm{~mL}$ of the dye solution was kept at a distance of $7 \mathrm{~cm}$ from the UV source with constant stirring of $60 \mathrm{rpm}$. In all the experiments a known weight of catalyst was added to known concentration of the dye solution and was allowed for 30 minutes in dark to attain the adsorption equilibrium and then the mixture was irradiated with UV light. A sample $(3 \mathrm{~mL})$ was withdrawn at regular intervals and centrifuged. Absorbance of the supernatant solution was measured using UVvisible spectrophotometer at $\lambda \max 565.5 \mathrm{~nm}$ and 
returned to the reactor. The structure of the dye, $A B$ 113 is given in figure 1.

\section{Characterisation techniques}

The x-ray powder diffraction patterns (XRD) were obtained using Rigaku X-ray diffractometer, Japan. The crystalline phase of $\mathrm{ZnO}$ was identified by comparing with JCPDS card no. 36-1451. The field emission scanning electron microscope (FESEM) and energy dispersive $\mathrm{x}$-ray diffraction (EDAX) photographs of $\mathrm{ZnO} / \mathrm{C} / \mathrm{Co}$ were obtained by using a high resolution scanning electron microscope (Carlzeiss, Supra 55, Germany). UV studies were carried out using SL 210 UV-visible double beam spectrophotometer.

\section{RESULTS AND DISCUSSION}

\section{Characterisation of the catalyst}

The crystal structure of the sample was investigated using XRD (Table 1).

As shown in the figure 2 , the $\mathrm{ZnO} / \mathrm{C} / \mathrm{Co}$ nanocomposite matches with the standard diffraction data for the hexagonal $\mathrm{ZnO}$ wurtzite structure (JCPDS No. 36-1451).

No characteristic peaks corresponding to a cobalt oxide phase were observed. This indicates that the concentration of cobalt oxide formed in the sample is too low to be measured ${ }^{26}$. The peaks at $2 \theta=31.73^{\circ}, 34.39^{\circ}, 36.22^{\circ}, 47.52^{\circ}, 56.55^{\circ}, 62.79^{\circ}$, $66.35^{\circ}, 67.90^{\circ}, 69.03^{\circ}$, and $72.54^{\circ}$ were assigned to (100), (002), (101), (102), (110), (103) , (112), (004) and (202) planes of $\mathrm{ZnO}$ nanoparticles, indicating that the formed nano particle was found to be polycrystalline Wurtzite structure. XRD patterns were identical to the hexagonal phase with Wurtzite structure with space group [C6V $=\mathrm{P}_{3} \mathrm{mc}$ ) and unit cell parameters $\mathrm{a}=\mathrm{b}=3.248 \AA$ and $\mathrm{c}=5.1$ $\AA$. The crystallite size was calculated from the following Debye Scherer formula,

$$
d=\frac{K \lambda}{B \operatorname{Cos} \theta_{B}}
$$

where $\mathrm{K}$ is 0.89 (Scherer's constant), $\lambda$ is the wavelength of $X$-rays, $B$ is the Bragg diffraction angle and $B$ is the full width at half-maximum

Table 1: XRD analysis of ZnO/C/Co nanocomposites

\begin{tabular}{llll}
\hline $\begin{array}{l}\text { S. } \\
\text { No }\end{array}$ & $\begin{array}{l}\text { Position } \\
\mathbf{2 \theta}(\mathbf{d e g})\end{array}$ & $\begin{array}{c}\text { Phase } \\
\text { name }\end{array}$ & $\begin{array}{c}\text { Size } \\
(\mathbf{n m})\end{array}$ \\
\hline 1. & 32.25 & 100 & 12.02 \\
2. & 34.86 & 002 & 11.49 \\
3. & 36.69 & 101 & 11.19 \\
4. & 56.98 & 110 & 12.09 \\
5. & 63.15 & 103 & 9.03 \\
6. & 68.47 & 112 & 5.33 \\
\hline
\end{tabular}

Table 2: EDAX analysis of $\mathrm{ZnO} / \mathrm{C} / \mathrm{Co}$ nanocomposites

Sample $\quad$ Elements (weight \%)

\begin{tabular}{ccccc} 
& OK & ZnK & CK & CoK \\
\hline ZnO/C/Co & 57.49 & 13.68 & 28.05 & 0.78
\end{tabular}<smiles>[NH3+]OS(=O)(=O)c1ccccc1N=Nc1ccc(N=Nc2ccc(Nc3ccccc3)c3c(S(=O)(=O)O)cccc23)c2ccccc12</smiles>

Fig. 1: Structure of acid blue 113 
(FWHM) of the highly intense diffraction peak. Using the Debye-Scherer formula, the average crystallite size of $\mathrm{ZnO} / \mathrm{C} / \mathrm{Co}$ was found to be $10.53 \mathrm{~nm}$ respectively. Furthermore, it could be seen that the diffraction peaks shown in figure 2 were more intensive and narrower, implying the good crystalline nature of the $\mathrm{ZnO} / \mathrm{C} / \mathrm{Co}$ nano composite as was observed in $\mathrm{ZnO}$ product. The particle size and surface morphology of $\mathrm{ZnO} / \mathrm{C} / \mathrm{Co}$ nanocomposites analysed by FESEM is shown in figure 3.

The FESEM image reveals that the entire product is comprised of spherical nano particles with the average size of $22 \mathrm{~nm}$. The EDX studies of

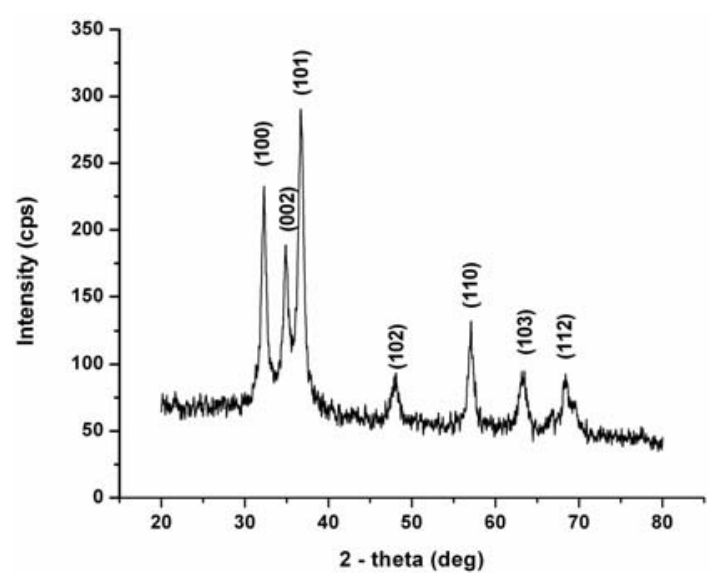

Fig. 2: XRD pattern of ZnO/carbon/ cobalt nano composite

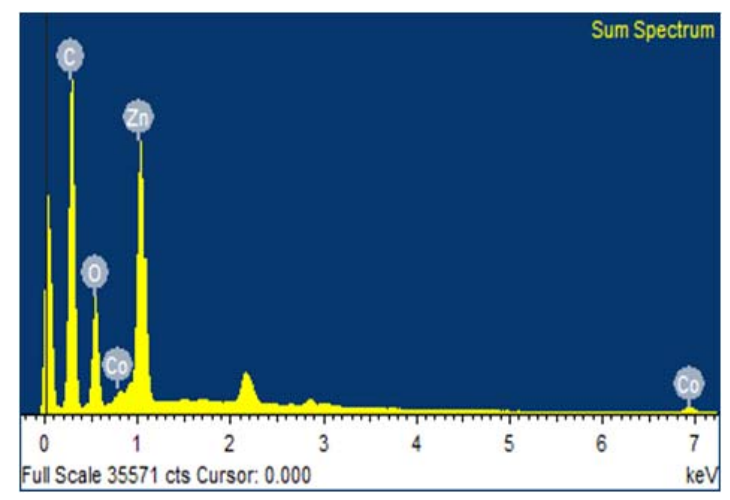

Fig. 4: EDAX elemental analysis of $\mathrm{ZnO} /$ carbon/ cobalt nano composite
$\mathrm{ZnO} / \mathrm{C} / \mathrm{Co}$ nanocomposite confirm the presence of zinc, cobalt and oxygen as the primary components which are shown by figure 4 .

The percentage of carbon loaded on to the catalyst samples were determined by EDAX analysis (Table 2).

\section{Photodegradation of Acid Blue 113}

The photo degradability of the dye was investigated by exposing the dye solution to UV light in the presence of photocatalysts such as nano $\mathrm{ZnO}$, nano $\mathrm{ZnO} / \mathrm{C}$ composite and nano $\mathrm{ZnO} / \mathrm{C} / \mathrm{Co}$ composite separately. It was observed that the nano $\mathrm{ZnO} / \mathrm{C} / \mathrm{Co}$ composite decolorizes the dye faster

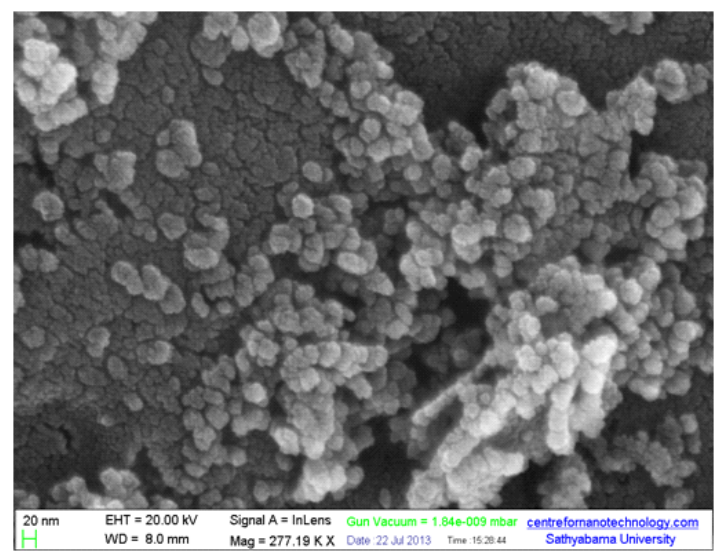

Fig. 3: FESEM image of ZnO/carbon/ cobalt nano composite

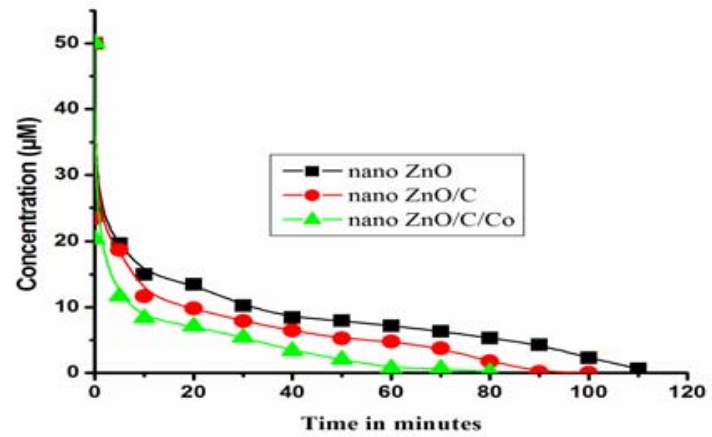

[Acid blue ] $=50 \mu \mathrm{M}$, Catalyst $=0.5 \mathrm{~g} / \mathrm{L} ; \mathrm{pH}=6.9$; Temperature $=30^{\circ} \mathrm{C} \pm 1.0$; incident wavelength $=254 \mathrm{~nm}$; Absorbance measured at $565.5 \mathrm{~nm}$.

Fig. 5: Photodegradability of [Acidblue113] 
than nano $\mathrm{ZnO} / \mathrm{C}$ composite and nano $\mathrm{ZnO}$. It was also observed that about $66 \%$ of the dye degraded within $10 \mathrm{~min}$ in the presence of nano $\mathrm{ZnO} / \mathrm{C} / \mathrm{Co}$ composite, where as in the presence of pristine nano $\mathrm{ZnO}$ and nano $\mathrm{ZnO} / \mathrm{C}$ composites the degradation of the dye was found to be $27 \%$ and $53 \%$ respectively as shown in figure 5 .

The higher degradation of nano $\mathrm{ZnO} / \mathrm{C} /$ Co composite may be attributed to the higher surface area of the catalyst and an enhanced adsorption due to carbon which is a prerequisite for photodegradation ${ }^{27}$. The preliminary results suggest that nano $\mathrm{ZnO} / \mathrm{C} / \mathrm{Co}$ composite can be used as effective photocatalyst for the degradation of dye acid blue 113 .

\section{CONCLUSIONS}

The nano $\mathrm{ZnO} / \mathrm{C} / \mathrm{Co}$ composite was found to be a more effective catalyst towards the degradation of acid blue 113 when compared to pristine nano $\mathrm{ZnO}$ particle and nano $\mathrm{ZnO} / \mathrm{C}$ composites. The optimum carbon loading in the catalyst $\mathrm{ZnO} / \mathrm{C} / \mathrm{Co}$ was maintained at $10 \%$. The dye removal was found to be maximum at a $\mathrm{pH}$ 6.9. The optimum catalyst loading was found to be $0.5 \mathrm{~g} \mathrm{~L}^{-1}$. The required time for $98 \%$ decolorization of the one liter of solution containing $50 \mu \mathrm{M}$ of dye at $\mathrm{pH} 6.9$ was $80 \mathrm{~min}$.

\section{REFERENCES}

1. Environmental Protection Agency, US Environmental protection agency report DC 2007: EPA100/B-07/001, EPA Washington

2. Rajkumar, D.; Jong, G. K. J. Haz. Materials. 2006, 136, 203-12

3. Kansal, S. K.; Singh, M.; Sud, D. J. Haz. Materials. 2007, 141, 581-90

4. Gouvea, C. A. K; Wypych, F.; Moraes, S. G.; Duran, N.; Nagata, N.; Zamora, P. P. Chemosphere. 2000, 40, 433-40

5. Neppolian, B.; Choi, H. C.; Sakthivel, S.; Banumathi, A.; Murugesan, V. J. Haz. Materials. 2002, 89, 303-17

6. Cristian, L.; Juanita, F.; Jaime, B.; Mansilla, H. D. Catalysis.today. 2002, 76, 235-246

7. Rajat, A.; Jitendra, V.; Punjabi, P. B.; Ameta, S. C. Indian J. Chem. Tech. 2006, 13, 114-118

8. Sivalingam, G.; Nagaveni, K.; Hegde, M. S.; Giridhar, M. Applied Catalysis B: Envir. 2003. 45, 23-28

9. Junping, L.;Yao, X.; Yong, L.; Dong, W.; Yuhan, S. China Particuolog. 2004, 2, 266-269

10. Changchun, C.; Jiangfeng, L.; Ping, L.; Benhai, Y. Advances in Chem. Engin. and Scien. 2011, 1, 9-14

11. Suwanboon, S.; Amornpitoksuk, P.; Haidoux, A.; Tedenac, J. C. J. Alloys Compd. 2008, 462, 335-339

12. Zu, P.; Tang, Z. K.; Wong, G. K. L.; Kawasaki,
M.; Ohtomo, A.; Koinuma, K.; Sagawa. Solid State Commun. 1997, 103, 459-463

13. Curri, M. L. Mater. Sci. Eng, 2003, 23, $285-$ 289

14. Muruganandham, M.; Wu, J. J. Appl. Catal. B: Environ. 2008, 80, 32-41

15. Daneshvar, N.; Salari, D.; Khataee, A. R. J. Photochem. and Photobiol. A: Chem. 2004, 162, 317-321

16. Noraidura, A.; Rusmidah, A.; Wan, A.; Wan, A. B.; Mohamed, N. G.; Mohemed, Y. O. Jurnal. Teknologi. 2007, 47, 1-14

17. Comparelli, R.; Fanizza, E.; Curri, M. L.; Cozzi, P. D.; Mascolo, G.; Agostiano, A. Appl. Catal. B. 2005, 60, 1-11

18. Zhang, L. W.; Cheng, H.Y.; Zong, R. L.; Zhu, Y. F. J. Phys. Chem. C. 2009, 113, 2368-2374

19. Fu, H. B.; Xu, T. G.; Zhu, Y. F. Environ. Sci. Technol, 2008, 42, 8064-8069

20. Wang, Z. C. ACS Nano. 2008, 2, 1987-1992

21. Xu, L.; Au, Y.; Pelligra, C.; Chen, C.; Jin, L.; Huang, H.; Sithambaram, S.; Aindow, M.; Joeshon, R.; Suib, S. L. Chem. Mater. 2009, 21, 2875-2885

22. Saleh, R.; Djaja, N. F. Spectrochimica Acta Part A: Molecular and Biomolecular Spectroscoy. 2014, 130, 581-90

23. Nocera, D. G. Inorg. Chem. 2009, 48, 10001 10017 
24. Duan, X.; Huang, Y.; Agrawal, R.; Lieber, C. 26. Lu, Y.; Lin, Y.; Wang, D.; Wang, L.; Xie, T.; Jiang, M. Nature, 2003, 1, 241-5

T. Nano Res, 2011, 4, 1144-1152

25. Jaya lakshmi, M.; Palaniappa, M.; 27. Muthirulan, P.; Meenakshisundararam, M.; Balasubramanian, K. Int. J. Electrochem. Kannan, N. J. Adv. Res, 2013, 4, 479-481 Science. 2008, 3, 96-103 